Military Technical College Kobry Elkobbah, Cairo, Egypt.

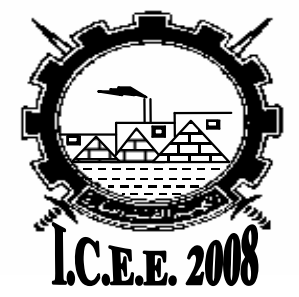

$4^{\text {th }}$ International Conference On

Chemical \& Environmental

Engineering

27-29 May 2008

\title{
A PROSPECTIVE PRESENTATION TO THE NANOTECHNOLOGY BENEFITS IN THE FIELD OF POLLUTION TREATMENTS AND CHEMICAL ENGINEERING PROCESSINGS
}

\author{
M.Z. Abdel Wahab*
}

\begin{abstract}
Nanotechnology is a new field exploring a new frontier ; a frontier that exists on a head of a pin. This new exploration had been done in atomic physics, $m$ electrical engineering , chemistry ,material science and in numerical physics. This exploration extends from the hundred microns diameter of a human hair to a fraction of a nanometer; the Size of a single atom. This new frontier is only half expored, uptil now.

The chemical engineering processings and pollution control treatments are intuitive examples from the other half which has not been yet explored, and which is a target to be explored in the near future

The applications of the chemical engineering science, technology and engineering in different life sectors are now accepting huge and widespread understanding from those who were opposing its importance in the past. Rare of the well known industries are not practising now chemical engineering operations, processings and/or techniques. Researches in such industrially applied sectors are advancing allover the world, aiming to ameliorate production rates and masses, as well as production qualities..

The nano-scale field of examinations and characterizations is being advancing since the year 1983 in a direction of precising knowledges about the transformation and transportation of the nano-particles consisting the media of reactions and productions, giving at last a precise capability of searching ways for better actions and processings on an applied productive scale. The characterization behaviours of different species in a system can be, thus, easily studied and evaluated in such a nano-scale study.

This lecture highlights some important sectors in which advances in chemical engineering may follow and proceed, aiming to find new trends, qualified routes and non-traditional techniques of productions in the near future. Examples of different advances in some other sectors are given so as to ensure prospectives in the chemical engineering field of researches and applications, as well as in the techniques of pollution treatments allied to chemical engineering operations.
\end{abstract}

\footnotetext{
* Professor of Chemical Engineering, Faculty of Engineering, Minia University
} 